\title{
The economic resilience of the Spanish provinces: From recession to recovery
}

\author{
JOSÉ VILLAVERDE (요 and ADOLFO MAZA*
}

\begin{abstract}
Department of Economics, Faculty of Economics, University of Cantabria, Avda de Los Castros, s/n.
\end{abstract} 39005, Santander, Spain

Received: March 16, 2018 • Revised manuscript received: May 17, 2018 • Accepted: May 27, 2018

(C) 2020 Akadémiai Kiadó, Budapest

\begin{abstract}
The purpose of this paper is to analyse the economic resilience of Spanish provinces and help to explain why some of them are much more resilient than others. To do so, the paper focuses on the recent, 20072009 economic crisis and computes a composite indicator (Resilience) made up of two sub-indicators: one for the recession period (Drop) and the other for the recovery period (Rebound). Then, it suggests some factors affecting resilience and, due to the presence of spatial dependence, applies a spatial econometric approach to assess them. The main conclusions are that the level of Resilience depends negatively on the shares of the construction and manufacturing sectors in GDP, and positively on the share of services and the openness degree. As for the Drop, it is important to stress that human capital emerges as a variable that has contributed to minimise the negative effect of the crisis.
\end{abstract}

\section{KEYWORDS}

resilience, employment, Spanish provinces, recession, recovery

JEL CLASSIFICATION INDICES

R10, R11, E32, C21

*Corresponding author. E-mail: mazaaj@unican.es 


\section{INTRODUCTION}

Although the interest on regional economic fluctuations has a long history, ${ }^{1}$ the use of the concept of economic resilience to account for them is relatively new. In fact, the literature on economic resilience has just blossomed in the last few years mainly because of the grim consequences produced by the Great Recession (GR) of 2007-2009. ${ }^{2}$ The economic crisis that ensued this recession has proved to be a too long-lasting phenomenon, to the point that in some countries, like Spain, it is still an ongoing event. Accordingly, the interest of analysts and policy makers on economic resilience is rocketing (Dabrowski 2016; Lastauskas - Stakenas 2017). This interest mainly comes from the fact that although economic recessions and recoveries tend to affect all parts (regions and provinces) of a country, there is usually a widespread territorial variation about when recessions and recoveries start and what is their extent and duration. This is indeed the case with the GR in most developed countries.

Spain is, within the European Union (EU), one of the countries that has suffered most after the GR shock (Malo 2015). Between the second quarter of 2008 and the first quarter of $2014,{ }^{3}$ nearly 3.4 million people lost their jobs, accounting for about $20 \%$ of Spain's initial employment. Although all Spanish provinces experienced an evolution trend rather similar to the national one, there were significant differences about the relative amplitude and duration of the decline, as there are in the strength and speed of the current recovery. This is shown in Figure 1, which



Figure 1. Evolution of employment $(2002 \mathrm{~T} 1=100)$

\footnotetext{
${ }^{1}$ For references about the first and more relevant papers on the issue, see Martin et al. (2016).

${ }^{2}$ Martin (2012) also adds three other reasons: the succession of major environmental disasters, the development of the concept in other disciplines, and the growing importance of an evolutionary perspective.

${ }^{3}$ For the whole country according to the Bank of Spain, the second quarter of 2008 represents the starting point of the crisis. The first quarter of 2014 reflects, according to most criteria, the turning point for the recovery.
} 
depicts the employment evolution of Spain and the two provinces that represent, with respect to the extent of the drop, the polar cases: Albacete and the Balearic Islands. In the first one, employment fall by $1.17 \%$ per quarter between the peak (3rd quarter of 2007) and the trough (4th quarter of 2012), while in the second the fall was just a mere $0.41 \%$ per quarter between the peak and the trough (4th quarter of 2008 and 2011, respectively).

The purpose of this paper is twofold. First, it aims at measuring the degree of economic resilience of the Spanish provinces (Figure 2) with respect to the GR shock. ${ }^{4}$ Second, it also tries to offer some plausible explanations on why the response to the GR shock varies so much from one province to another. To the best of our knowledge, Rios et al. (2017) and, to a lesser extent, Cuadrado-Roura - Maroto (2016) and Reig (2017) have tried to do so at the regional level (Nomenclature of Territorial Units for Statistics (NUTS2)), while Angulo et al. (2018) have done it at the provincial level. ${ }^{5}$ As far as we are aware of, no paper (neither for Spain nor for any other country) has adopted a spatial econometric approach to deal with this issue. We aim to fill this gap in the literature as the presence of spatial dependence on resilience can affect the reliability of the findings.

The paper is structured as follows. After briefly reviewing the concept of resilience and its use in economics in Section 2, it proceeds to operationalise and apply it to the Spanish provinces in Section 3. Next, by estimating a spatial model Section 4 provides some tentative explanations of the differences in the degrees of provincial resilience. Finally, Section 5 offers the main conclusions and some, admittedly very loose, tentative policy remarks.

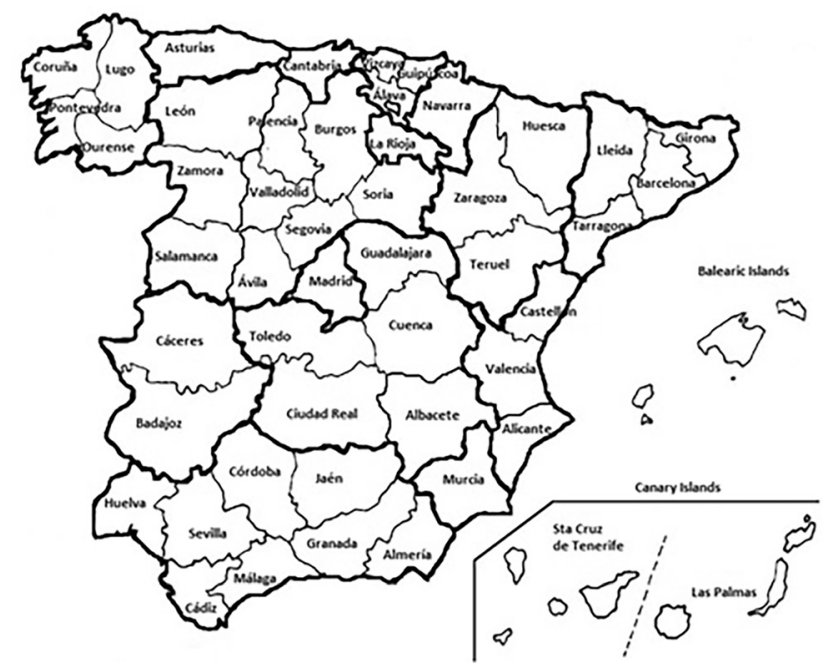

Figure 2. Provincial map of Spain

\footnotetext{
${ }^{4}$ Considering data availability, this NUTS3 disaggregation is the highest level of spatial disaggregation possible regardless of the variable used to deal with resilience.

${ }^{5}$ Angulo et al. (2018), using a shift-share approach, provide interesting findings about the role played by the industry-mix in explaining resilience.
} 


\section{THE MEANING OF ECONOMIC RESILIENCE}

Although the use of the concept of resilience is rather new in the area of economics, ${ }^{6}$ it has been employed for about four decades or so in other research fields, in particular in those related to physics, ecology, and engineering. Resilience comes from the Latin word resiliere which means "to recoil or spring back into shape after bending, stretching or being compressed" (Oxford Dictionary of English 2010); puts it in other words, resilience refers to the way a system reacts to and recovers from a negative shock.

While the notion of resilience "is rapidly becoming part of the conceptual and analytical lexicon of regional and urban economic studies" (Martin - Sunley 2015: 2), it is still somewhat contentious (Martin 2012), especially among economic geographers. ${ }^{7}$ In essence, the concept of resilience refers to the capacity of a territory (country, region or province) to withstand an economic shock and respond positively to it. In this sense, economic resilience is something in between "engineering", "ecological" and "adaptive" resilience. The link among these three perspectives of resilience and the economic one is that the engineering view reminds us of the so-called plucking model (Friedman 1993), the ecological view relates to the concept of hysteresis (Georgescu-Rogen 1967), and the adaptive resilience is linked to the Schumpeterian idea of creative destruction. ${ }^{8}$

The capacities to resist (withstand) to and recover (respond positively) from a shock are, in fact, two main dimensions of the economic resilience. However, and in connection with the aforementioned ways of looking at the economic resilience, Martin (2012) also refers to the long-term capacity to adapt (structural capacity to re-orientate the economy) and to the degree to which the growth path prior to the shock is resumed. ${ }^{9}$ Therefore, as pointed out by Sensier et al. (2016: 131), "there is an emerging consensus that regional economic resilience may be defined as the capacity of a regional or local economy to withstand, recover from and reorganize in the face of market, competitive and environmental shocks to its development path".

\section{MEASURING RESILIENCE IN THE SPANISH PROVINCES}

A key issue with the economic resilience concept is how to operationalise it. There are different proposals in the literature ${ }^{10}$ but most of them refer just to some of the dimensions previously mentioned and more specifically to the first two (the capacities to withstand and bounce back), taken on an individual basis. Although there are some papers that have proposed the use of a composite index, here we follow the approach pioneered by Han - Goetz (2015) because their

\footnotetext{
${ }^{6}$ Reggiani et al. (2002) seem to be among the first analysts in applying this concept in economics. For a survey on the issue, see Modica - Reggiani (2015).

${ }^{7}$ See, among others, Hassink (2010) and MacKinnon - Derickson (2013).

${ }^{8}$ For a thorough review of these different notions of resilience, see Martin (2012).

${ }^{9}$ Davies (2011) merges these two last dimensions in just one concerning the long-term adaptability of the regional economics.

${ }^{10}$ Briguglio et al. (2009), Kahsai et al. (2015) and Sensier et al. (2016) offer, among others, good references on this issue.
} 
indicator captures the two aforementioned dimensions of resilience jointly. ${ }^{11}$ This indicator, conveniently adapted, is used to measure the Spanish provincial resilience. Needless to say, as the economic crisis is an ongoing phenomenon in Spain, we cannot pay attention to other dimensions of resilience, in particular to those referring to the long-term capacity to adapt.

Anyway, before referring to the indicators proposed to measure resilience, it is important to clarify our benchmark or reference state, simply because resilience is, above all, a relative concept (Martin - Sunley 2015). Therefore, the resilience of any territory (provinces in our case) can only be gauged against either that of a broader territory (the entire country, for instance) or against the expected path of the variable under analysis in the territory under consideration (province) in the absence of a shock. Martin (2012) has proposed the use of the first approach (what we are going to call the country approach), ${ }^{12}$ while the second (what we call the business cycle approach) has been advanced by Han - Goetz (2015) and partially adopted by Martin et al. (2016). In the country approach, which allows knowing whether a province is more or less resilient that the whole country, the starting dates of both recessions and recoveries and, therefore, their duration, are considered the same as the average of the country for all provinces. On the contrary, in the business cycle approach both the starting dates and the duration of recessions and recoveries may differ across the provinces. For this reason, we consider this second approach more relevant as it does not impose such a strong time-constraint as the first one. In addition, using the country approach would be equivalent to admitting that 'in the country of the blinds the one-eyed man is the king'. The business cycle approach, however, takes into consideration how the evolution of each province before the burst of the GR was, something that is somewhat overlooked if you simply compare its performance after the shock with the one developed by the whole country. Having said that, here we have to admit that the business cycle approach also has an important drawback: it assumes regularity in the business cycle, which is somewhat at odds with reality. In any case, once pros and cons of the two approaches are weighted against each other, we believe that the business cycle approach is better suited to address the analysis of resilience, so it is the one used in this paper.

Once we have chosen the reference state, it is also important to decide that to which variable(s) the concept of resilience is going to be applied. The two more common variables used for this purpose are GDP and employment. ${ }^{13}$ In this paper, we opted for the employment variable (taken from the Economically Active Population Survey published by the Spanish Statistical Office (INE)) for three reasons. First, because what happens to employment over a recessionary period seems to be more relevant to the well-being and welfare of people than what happens to GDP. Second, because employment data are less prone to experience statistical revisions than GDP data. Third, because we think it is more informative to use quarterly data in the analysis and this type of data does not exist for Spanish GDP at the provincial level. Obviously, the use of

\footnotetext{
${ }^{11}$ Rios et al. (2017) also applied a somewhat modified version of this index.

${ }^{12} \mathrm{He}$ computes the so-called sensitivity index as the ratio between the percentage change in employment in the territory under analysis (region, province, etc.) to the change in national employment.

${ }^{13}$ Other typical economic variables used to calibrate resilience are unemployment (in absolute or relative terms) and household income.
} 
quarterly data requires applying a method of seasonal adjustment. In this case, we have used the program TSW64+ ${ }^{14}$ as it is the one employed by INE for these purposes.

Having decided about the reference state and the variable used to measure the economic resilience we consider that, in order to operationalise it, it is useful to refer to Figure 3, which represents the phases of a typical business cycle. In the figure, $\mathrm{P}$ represents the peak $\left(\right.$ at $\left.t_{1}\right)$ or the maximum of the expansion phase, $\mathrm{T}$ is the trough or minimum of the recession period (at $\left.t_{2}\right)$, $\mathrm{DC}$ is the duration of the recession, and DR is the duration of recovery. The drop or resistance is the capacity to absorb or withstand a shock, while the rebound or bounce back reflects the amplitude and speed of the recovery.

A key point in measuring resilience relates to the correct dating of the shocks. Although there is a large literature on this issue, ${ }^{15}$ here, as the GR was exactly the result of a financial shock, we follow what the IMF noted for this type of shocks, specifically that dating a shock "is typically based on qualitative and judgemental analyses" (Claessens - Kose 2013: 4). This being the case, we follow the convention that a peak terminates an expansion and a trough terminates a recession (Artis et al. 2004); therefore, the length of a recession after a shock goes from the date of the peak to that of the trough. Anyway, in order to consider a recession as such, we assume that it happens when there are at least two consecutive quarters in which the employment declines, with this fall being in total larger than $3 \%{ }^{16}$ of the peak value.

Following Han - Goetz (2015), the computation of economic resilience for the Spanish provinces involves three steps. First, to estimate the magnitude of the drop during the recession (between the corresponding $t_{1}$ and $t_{2}$ for each province) we need to know both the actual $\left(e_{t 2}\right)$

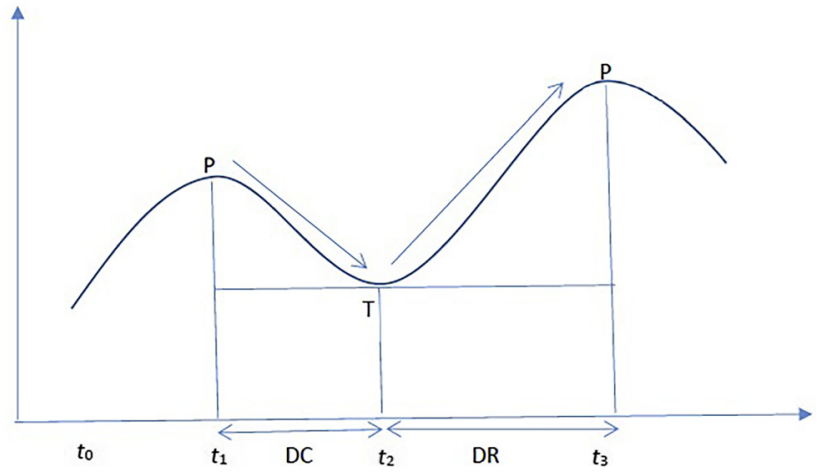

Figure 3. Business cycle

\footnotetext{
${ }^{14}$ TSW is a windows extension of the programs Tramo (Time Series Regression with ARIMA Noise, Missing Observations and Outliers) and Seats (Signal Extraction in ARIMA Time Series), developed by Gómez - Maravall (1996). For a revised version, the one used in this paper, see Caporello - Maravall (2004).

${ }^{15}$ An interesting reference is Artis et al. (2004).

${ }^{16}$ Paraphrasing Sensier et al. (2016), if the fall in employment is less than 3\%, we consider that the shock is more a tremor than an earthquake. When evaluating resilience, we mostly refer to economic earthquakes.
} 
and the "expected" $\left(\widehat{e_{t 2}}\right)$ levels of employment at the date of the trough $\left(t_{2}\right) .{ }^{17}$ To compute $\widehat{e_{t 2}}$ for each province, we calculate its compound employment growth rate under the assumptions that employment follows the same trend after the shock than before it; this compound growth rate is estimated over the period going from $t_{0}$ (that in our case is always the first quarter of 2002) to $t_{1}$ (Figure 3). Then, the drop is given by the expression:

$$
\operatorname{Drop}(D)=\frac{\widehat{e_{t 2}}-e_{t 2}}{\widehat{e_{t 2}}}
$$

Second, to calculate the extent of the rebound in the recovery between the trough and the peak, ${ }^{18}$ we compute the expression:

$$
\text { Rebound }(\mathrm{Re})=\frac{e_{t 3}-e_{t 2}}{e_{t 2}} * \frac{1}{t_{3}-t_{2}}
$$

in which $e_{t 3}$ refers to the actual employment level in $t_{3}$. Finally, to calculate the degree of the resilience it is necessary to combine the Drop and Rebound indicators in order to obtain a composite one. Of the many possibilities to do it, we adopted the one used by Han - Goetz (2015) for which we define a ratio combining both the Drop and Rebound indicators such as:

$$
\text { ratio }=\ln \left(\frac{\text { Rebound }-\min (\text { Rebound })+s}{\text { Drop }-\min (\text { Drop })+s}\right)
$$

where, to make sure that the expression in brackets is a positive number, we include the smallest value among all provinces (min) and a small number (0.0001) denoted by $s .{ }^{19}$ Then we normalise this composite indicator by taking away its mean and dividing this result by the standard deviation of the series. Therefore, the Resilience indicator is as follows:

$$
\text { Resilience }(R)=\ln \left(\frac{\text { ratio }- \text { mean }(\text { ratio })}{\text { stdev }(\text { ratio })}\right)
$$

Applying the three steps mentioned above, Table 1 shows, for each province, the quarter in which the (peak and trough) turning points took place, the duration of the drop, and the ranking in the Resilience, Drop and Rebound indices. As can be seen, the range of the results is quite wide. Among the provinces that showing a high level of resilience, some of them (Islas Baleares, Lugo, Navarra, and Vizcaya) are so because of their capacity to withstand the GR in spite of not being very active when it comes to the recovery. At the same time, there are other provinces (mainly Soria, and to a lesser extent Jaén, Cuenca, and Las Palmas) with a high degree of resilience based on their capacity to rapidly recover from the recession, although they were

\footnotetext{
${ }^{17}$ This approach is in agreement with the definition of the regional economic resilience provided by Hill et al. (2008).

${ }^{18}$ As the recovery phase has not been completed yet, in that the employment level in most provinces is currently much lower than what it was at the start of the recession, we consider that peak means the last quarter for which there is information that is the second quarter of 2017.

${ }^{19}$ The Ratio indicator is so defined for the sake of interpretation. Needless to say, the lower (higher) the Drop (Rebound), the higher the Resilience, so that the first one is in the denominator while the second is in the numerator.
} 
Table 1. Resilience, drop and rebound indicators

\begin{tabular}{|c|c|c|c|c|c|c|}
\hline \multirow[b]{2}{*}{ Province } & \multirow[b]{2}{*}{ Peak } & \multirow[b]{2}{*}{ Trough } & \multirow[b]{2}{*}{ Amplitude of the recession* } & \multicolumn{3}{|c|}{ Ranking } \\
\hline & & & & Resilience & Drop & Rebound \\
\hline Balears (I.) & 2008Q2 & $2011 Q 4$ & 12 & 1 & 1 & 27 \\
\hline Lugo & $2008 Q 3$ & 2014Q2 & 23 & 2 & 2 & 37 \\
\hline Navarra & $2008 Q 3$ & $2013 Q 2$ & 19 & 3 & 3 & 42 \\
\hline Soria & $2008 Q 1$ & $2016 Q 1$ & 32 & 4 & 20 & 1 \\
\hline Vizcaya & $2008 Q 2$ & $2014 Q 1$ & 23 & 5 & 4 & 43 \\
\hline Coruña (A) & $2009 Q 1$ & $2014 Q 1$ & 20 & 6 & 8 & 36 \\
\hline Burgos & $2008 Q 4$ & $2013 Q 2$ & 18 & 7 & 6 & 39 \\
\hline Valladolid & $2008 Q 4$ & $2014 Q 1$ & 21 & 8 & 5 & 47 \\
\hline Palencia & $2008 Q 1$ & 2014Q3 & 23 & 9 & 16 & 15 \\
\hline Segovia & $2008 Q 3$ & $2012 Q 4$ & 17 & 10 & 11 & 34 \\
\hline Jaén & $2008 Q 2$ & 2013Q1 & 19 & 11 & 26 & 8 \\
\hline Zaragoza & $2008 Q 3$ & $2014 Q 1$ & 22 & 12 & 22 & 13 \\
\hline Ourense & $2008 Q 4$ & $2016 Q 1$ & 29 & 13 & 23 & 14 \\
\hline Cuenca & $2008 Q 3$ & $2014 Q 3$ & 24 & 14 & 38 & 3 \\
\hline Palmas (Las) & $2007 Q 3$ & $2014 Q 3$ & 28 & 15 & 39 & 4 \\
\hline Huelva & $2008 Q 2$ & 2013Q1 & 19 & 16 & 31 & 11 \\
\hline Madrid & $2008 Q 3$ & 2014Q1 & 22 & 17 & 15 & 25 \\
\hline Granada & $2008 Q 1$ & $2013 Q 3$ & 22 & 18 & 35 & 7 \\
\hline Cádiz & 2008Q2 & $2014 Q 3$ & 25 & 19 & 45 & 2 \\
\hline Tenerife & $2007 Q 4$ & 2013Q1 & 21 & 20 & 19 & 18 \\
\hline Girona & $2008 Q 3$ & $2012 Q 2$ & 15 & 21 & 9 & 46 \\
\hline Badajoz & $2008 Q 3$ & $2012 Q 2$ & 15 & 22 & 12 & 41 \\
\hline Málaga & $2007 Q 4$ & 2013Q4 & 24 & 23 & 42 & 9 \\
\hline Zamora & $2007 Q 3$ & 201301 & 22 & 24 & 43 & 5 \\
\hline Guipúzcoa & $2008 Q 3$ & $2013 Q 3$ & 20 & 25 & 10 & 45 \\
\hline Ávila & $2008 Q 1$ & 2014Q4 & 27 & 26 & 44 & 6 \\
\hline Sevilla & $2008 Q 2$ & $2013 Q 4$ & 22 & 27 & 29 & 16 \\
\hline Cantabria & $2008 Q 3$ & 2013Q2 & 19 & 28 & 14 & 38 \\
\hline Barcelona & 2008Q2 & 2013Q2 & 20 & 29 & 21 & 23 \\
\hline
\end{tabular}


Table 1. Continued

\begin{tabular}{|c|c|c|c|c|c|c|}
\hline \multirow[b]{2}{*}{ Province } & \multirow[b]{2}{*}{ Peak } & \multirow[b]{2}{*}{ Trough } & \multirow[b]{2}{*}{ Amplitude of the recession* } & \multicolumn{3}{|c|}{ Ranking } \\
\hline & & & & Resilience & Drop & Rebound \\
\hline Ciudad Real & $2008 Q 2$ & $2015 Q 1$ & 27 & 30 & 40 & 12 \\
\hline Alicante & $2008 Q 1$ & $2012 Q 4$ & 19 & 31 & 25 & 19 \\
\hline Rioja (La) & $2008 Q 3$ & 201302 & 19 & 32 & 17 & 31 \\
\hline Asturias & $2008 Q 3$ & $2013 Q 2$ & 19 & 33 & 18 & 35 \\
\hline Salamanca & $2008 Q 1$ & $2014 Q 1$ & 24 & 34 & 7 & 48 \\
\hline Valencia & $2008 Q 2$ & $2013 Q 2$ & 20 & 35 & 24 & 30 \\
\hline Murcia & $2008 Q 1$ & $2013 Q 2$ & 21 & 36 & 36 & 20 \\
\hline Guadalajara & $2008 Q 4$ & $2013 Q 4$ & 20 & 37 & 27 & 32 \\
\hline Cáceres & $2007 Q 1$ & $2012 Q 2$ & 21 & 38 & 30 & 28 \\
\hline Córdoba & $2008 Q 2$ & $2013 Q 4$ & 22 & 39 & 34 & 22 \\
\hline Huesca & $2008 Q 3$ & 201304 & 21 & 40 & 33 & 29 \\
\hline Pontevedra & $2008 Q 1$ & $2015 Q 1$ & 28 & 41 & 37 & 26 \\
\hline Tarragona & $2008 Q 1$ & 2013Q1 & 20 & 42 & 41 & 24 \\
\hline Almería & $2006 Q 3$ & $2013 Q 3$ & 28 & 43 & 50 & 10 \\
\hline Albacete & $2007 Q 3$ & $2012 Q 4$ & 21 & 44 & 49 & 17 \\
\hline Toledo & $2008 Q 2$ & $2014 Q 1$ & 23 & 45 & 46 & 21 \\
\hline León & $2007 Q 4$ & $2013 Q 4$ & 24 & 46 & 28 & 44 \\
\hline Teruel & $2007 Q 4$ & 2014Q1 & 25 & 47 & 48 & 33 \\
\hline Castellón & $2008 Q 1$ & 2013Q2 & 21 & 48 & 47 & 40 \\
\hline Lleida & $2008 Q 3$ & 2014Q1 & 22 & 49 & 32 & 49 \\
\hline Álava & $2008 Q 3$ & $2014 Q 1$ & 22 & 50 & 13 & 50 \\
\hline
\end{tabular}

Note: $\left({ }^{*}\right)$ In quarters.

initially not able to properly absorb the shock. ${ }^{20}$ On the other hand, some provinces, such as Alava and Lleida, report a low level of resilience that is clearly marked by their lack of recovery, while in the cases of Toledo, Teruel, and Almería the main reason behind this low resilience was the intense drop of employment. Finally, there are also provinces showing either a good or a bad performance in both sub-periods: these are, for instance, the cases of Palencia, Zaragoza, and

\footnotetext{
${ }^{20}$ These findings are in line with those obtained, for a sample of the European countries, by Davies. According to her, the performances of the provinces in the downturn and the recovery "are not necessarily consistent, with some regions showing good resilience to the downturn in 2009 but poor resilience in 2010" (Davies 2011: 380).
} 


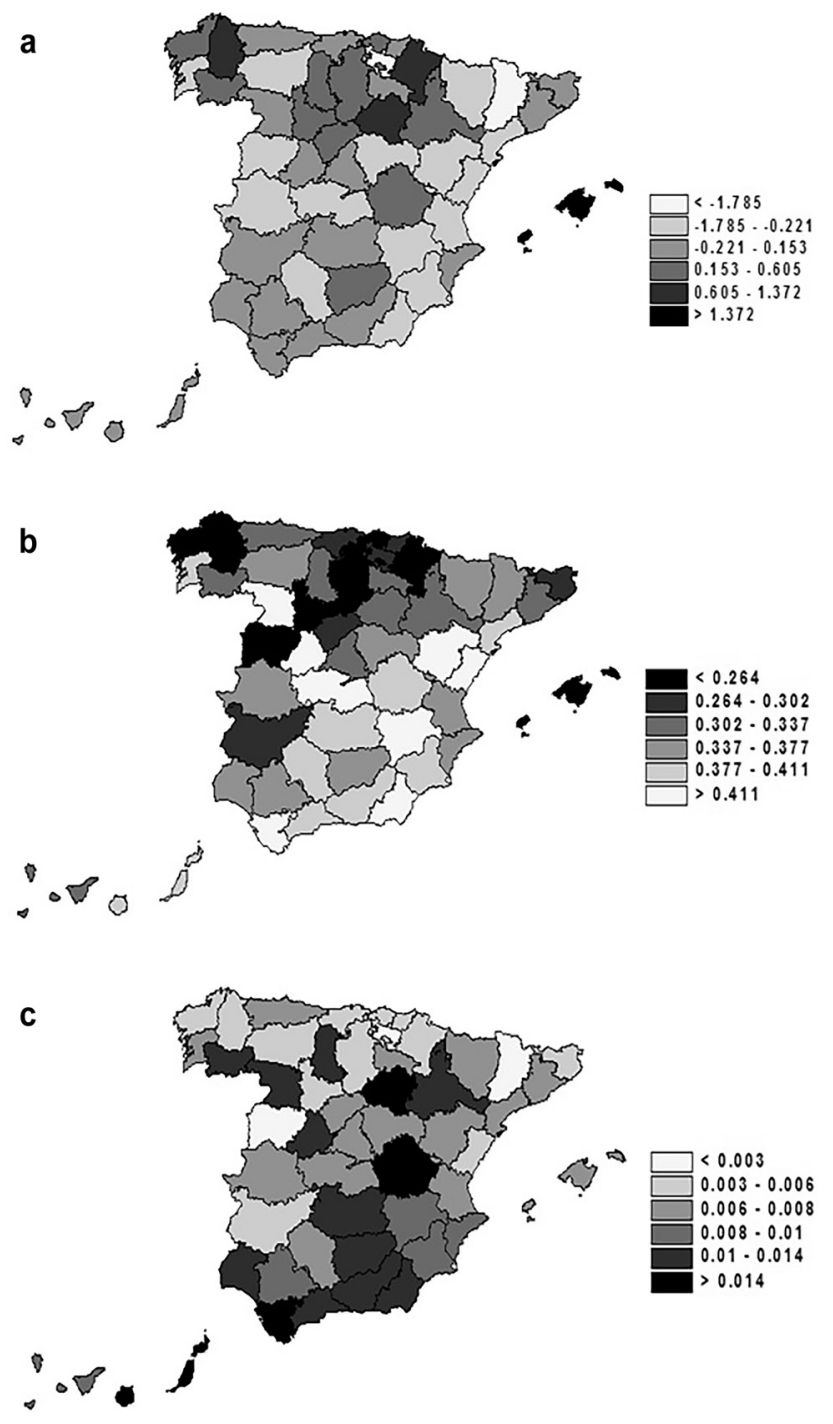

Figure 4. Spatial distribution of the Resilience (a), Drop (b) and Rebound (c) indicators

Orense (low drop and high rebound) and Castellón, Huesca and Cáceres (intense drop and weak rebound). It can be said that the results are quite heterogeneous and, at least for the case of Spain, the somewhat general conclusion that the better the initial situation is the higher the capacity of a region/province to face a shock (e.g. Fratesi - Rodríguez-Pose 2016; Di Caro Fratesi 2017) is not so obvious.

Although the results shown in Table 1 are rather illustrative, a map is very likely the best choice to present them; especially when, as in here, the information refers to the geographical 
locations. In this respect, Figure 4 displays the indicators for Resilience, Drop and Rebound (4a, $4 \mathrm{~b}$, and $4 \mathrm{c}$, respectively). For the sake of the interpretation, the darker the colour the better the situation (namely, the higher the resilience and rebound, and the lower the drop) is. As mentioned earlier, there appear to be quite remarkable differences in the performance of provinces over the drop and recovery phases. As for the drop, the North-western provinces performed better than the Southern ones, being the opposite true during the recovery. Overall, it seems that there is no clear geographical pattern with regard to the Resilience indicator.

However, we recommend a bit of caution when interpreting the maps since the conclusions to be drawn are highly sensitive to the number and width of the intervals used to represent each indicator. To check whether the initial impression gained from the previous figures is correct, we compute the most widely used and best-known test for spatial dependence, Moran's I statistic (Moran 1948). This is given by:

$$
I=\frac{N}{\sum_{i=1}^{N} \sum_{j=1}^{N} w_{i j}} \frac{\sum_{i=1}^{N} \sum_{j=1}^{N} w_{i j}\left(y_{i}-y\right)\left(y_{j}-y\right)}{\sum_{i=1}^{N}\left(y_{i}-y\right)^{2}}
$$

for $i \neq j$, where $y_{i}\left(y_{j}\right)$ is the corresponding indicator at province $i(j)$ - in this case, the Resilience, Drop and Rebound indices $-y$ is the mean of each indicator, $w_{i j}$ is an element of the distance matrix $W$ between each pair of the provinces and $\sum_{i=1}^{N} \sum_{j=1}^{N} w_{i j}$ is a standardisation factor that corresponds to the sum of all the weights and $N$ is the total number of provinces. A significant positive value of standardised Moran's I statistic indicates positive spatial dependence (autocorrelation), while a significant negative value reflects a pattern of spatial association between dissimilar values.

The results obtained for each indicator, using the inverse of the standardised distance as a distance matrix with the minimum cut-off that is needed to make sure that every province has at least one neighbour, ${ }^{21}$ are reported in Table 2. These results reveal that there is no spatial dependence for the Resilience indicator. However, for the Rebound and the Drop indicators, they

Table 2. Moran's I statistic

\begin{tabular}{|l|c|c|}
\hline Tests & Statistic & P-value \\
\hline Resilience & -0.035 & 0.210 \\
\hline Drop & $0.074^{* * *}$ & 0.000 \\
\hline Rebound & $0.010^{*}$ & 0.074 \\
\hline
\end{tabular}

Source: Own elaboration.

Notes: ${ }^{* * *}$ Significant at $1 \%$; ${ }^{*}$ Significant at $10 \%$.

\footnotetext{
${ }^{21}$ In any case, we also tried other distance matrices (inverse distance matrix, several k-nearest neighbour matrices) and the results were relatively similar.
} 
show the presence of a positive spatial dependence. Although somewhat striking, this is the typical case in which you realise that an aggregate indicator is masking what happens within its components.

Overall, it seems that, based on these results, there are some signs of spatial dependence (autocorrelation). Therefore, spatial dependence should be considered in the rest of the paper when it comes to explaining the resilience. Otherwise, our conclusions could be misleading or plainly wrong.

\section{EXPLAINING RESILIENCE}

Once the aggregate indicator of Resilience has been computed, the aim of this section is to try to uncover some of the reasons explaining the quite remarkable differences existing among the provinces. Taking advantage of the fact that the recession period is already over, we will also perform the same analysis for the Drop indicator. As for the recovery period, we believe that, as it is still in process and in some provinces has been working for only a few quarters, it would be quite daring to try to find the factors explaining the provincial differences in the Rebound indicator.

Before presenting the model, we think it is compulsory to clarify three points. To start with and to properly address the issue of the potential presence of a spatial dependence, we first estimate a non-spatial version of the model and then test for the presence of the spatial dependence in it. Second, to somewhat deal with the potential endogeneity problems in some of the explanatory variables, we decide to use 2002-2007 period averages for all of them. Third, that although some additional variables which could, on a priori basis, help explain the level of resilience were initially included in the model, and we finally opted for removing them as they did not significantly contribute to increase the goodness of fit of the model; in other words, we chose the variables that best describe the data (forward variable selection process). ${ }^{22}$

Bearing these considerations in mind, we firstly estimate the following non-spatial model for both the Resilience (R) and the Drop (D) indicators by ordinary least squares (OLS) (results available upon request):

$$
R(D)_{i}=\alpha_{i}+\beta_{1} G D P p c_{i}+\beta_{2} U R_{i}+\beta_{3} M_{i}+\beta_{4} C_{i}+\beta_{5} S_{i}+\beta_{6} H C_{i}+\beta_{7} X_{i}+\beta_{8} P D_{i}+u_{i}
$$

where $i$ denotes the province under consideration. As for the explanatory variables finally included in the model, some comments about data sources, metrics, definitions and expected signs are mandatory. Here we refer to the expected signs for the Resilience indicator $(R)$; needless to say, the opposite sign, if any, would be expected for the Drop indicator $(D)$. These variables are the following:

- Per capita Gross Domestic Product (GDPpc): Taken from the Spanish Regional Accounts published by INE and defined as GDP/inhabitants; we take it in logs. The expected effect of

\footnotetext{
${ }^{22} \mathrm{We}$ also tried with patents as a proxy for innovation (Bristow - Healy 2017), a proxy for social capital in line with the reasoning of Storper (2005) and Fratesi - Perucca (2017), net migration rates, the openness degree as an alternative to exports, and GDP as an alternative to per capita GDP. As we are analysing this issue at the provincial level, we did not consider any measure of the degree of autonomy; in any case, Hernandez-Salmeron and Usabiaga (2017) show that, using the Spanish regions as the case study, political decentralisation does not significantly affect the regional economic performance.
} 
this variable is somewhat unclear. On the one hand, it appears to be a stylized fact that the richest economies are better prepared to face adverse shocks. On the other hand, there is some empirical evidence at the country level showing that poor countries have kept higher growth rates than rich countries in the aftermath of the great recession (Frankel - Saravelos 2012).

- Unemployment Rate (UN): Taken from the Economically Active Population Survey (INE) and defined as the share of the labour force that is jobless; it is expressed in percentage points. A negative sign is expected for this variable as the capacity of an economy to tackle an adverse shock is reduced the higher its initial level of unemployment is (Briguglio et al. 2009).

- Manufacturing Industry $(M)$, Construction (C) and Services (S): ${ }^{23}$ These three variables are from the Spanish Regional Account (INE), defined as the respective share of GDP produced by each sector, and given in percentage points. The expected effect of manufacturing on resilience is negative as this sector is quite vulnerable to economic shocks (Davies 2011; Sensier Artis 2016). Regarding construction, a negative sign is expected as this sector has been the most severely hit by the economic crisis (Davies 2011). As for services, the first thing we want to stress is that we do not include government services in this variable because, as suggested by a referee, this kind of services has been probably less affected by the economic downturn than the rest. Regarding the expected sign, it is well known that the service sector has faced the crisis better than the remaining ones, so that a positive sign is expected.

- Human Capital (HC): Collected from The Valencian Institute of Economic Research (IVIE), defined as the share of population with tertiary education, and given in percentage points. In theory, the areas with people with high educational attainment are "likely to conduct more efficient searches and are less prone to layoffs" (Rios et al. 2017: 11), so the expected sign should be positive. ${ }^{24}$ However, this is not that clear for the Spanish case. This is so because the labour market is characterised by large polarisation (Anghel at al. 2013) and, due to the housing bubble, there was a huge demand for low-skilled workers in the past (De Ville Vermeiren 2016); in this setting, some provinces were/are not able to absorb their supply of skilled labour.

- Exports $(X)$ : Taken from the DATACOMEX databank published by the Ministry of Economy, Industry and Competitiveness, and defined as the share of exports on GDP. The sign of exports is indeterminate. On the one side, if exports are used as a way of fleeing from the crisis, it seems that it has to be positive. Additionally, economic areas implementing outwardlooking policies can be able to better face negative shocks (Combes - Guillaumont 2002). On the other side, one of the main results of previous research dealing with this issue refers to the vulnerability of the countries with export manufacturing economies to international upheavals (Davies 2011); this being so, the sign would be negative. ${ }^{25}$

- Population Density (PD): Taken from the Municipal Register database (INE), defined as the ratio of population to area and given as thousands of inhabitants per square kilometre. Here

\footnotetext{
${ }^{23} \mathrm{We}$ also tried with a sectoral specialisation indicator rather than the share of different sectors (see Kemeny - Storper 2015 for an in-depth analysis of the relationship between specialisation and regional development), but it did not improve the goodness of fit of the model.

${ }^{24}$ In the same vein, Eriksson - Hane-Weijman (2017) conclude that the regions with many high-skilled related industries are more resilient than others.

${ }^{25}$ For a comprehensive analysis of the effects of the balance of payments on economic performance for the Spanish regions see Bajo-Rubio - Diaz-Roldan (2015).
} 
the general idea is that low population density increases vulnerability and, therefore, reduces resilience. Putting another way, the metropolitan areas, because of the presence of agglomeration economies, seem to be more prepared to face shocks. Then, a positive sign is expected.

The next step is to test for the presence of spatial dependence in the model because, if this were to happen, the results of a non-spatial approach could be inconsistent (see e.g. LeSage Pace 2009). To address this issue, a series of Lagrange multiplier (LM) tests are computed on the residuals of the OLS estimation of Eq. (1) for both the Resilience $(R)$ and Drop $(D)$ indicators. We use the Lagrange multiplier test for spatial error dependence (LM-ERR) and its robust LMERR i.e. LM-EL version, in which null hypotheses are the absence of residual spatial autocorrelation, and the Lagrange multiplier test for spatial lag dependence (LM-LAG) and its robust LM-LAG i.e. LM-LE version, in which null hypotheses are the absence of substantive dependence. The results, displayed in Table 3, reveal that in the case of substantive spatial autocorrelation the hypothesis is rejected at the standard levels. Thus, the conclusion is that there is a (substantive) spatial dependence in the estimation and, therefore, the model based on Eq. (1) would not yield plausible results.

Hence, our model should incorporate a spatial lag of the dependent variable. We do so by estimating, by maximum likelihood, a panel Spatial Autoregressive Model (SAR) as follows:

$$
\begin{aligned}
R(D)_{i}= & \alpha_{i}+\beta_{1} G D P p c_{i}+\beta_{2} U R_{i}+\beta_{3} M_{i}+\beta_{4} C_{i}+\beta_{5} S_{i}+\beta_{6} H C_{i}+\beta_{7} X_{i}+\beta_{8} P D_{i} \\
& +\beta_{9} \sum_{j} w_{i j} R(D)_{i}+\mu_{i}
\end{aligned}
$$

Table 4 shows the estimation results. As can be seen, the effects of per capita income and unemployment rates are not statistically significant in any case. This result is not surprising in the first case but is quite startling in the second. A possible explanation is that, being in the habit of suffering relatively high unemployment rates even in the boom times, its increase throughout the recession have not much affected the employment performance of the provinces.

Table 3. LM tests for spatial dependence

\begin{tabular}{|l|l|l|l|l|}
\hline \multirow{2}{*}{ Tests } & \multicolumn{2}{|c|}{ Resilience (R) } & \multicolumn{2}{c|}{ Drop (D) } \\
\cline { 2 - 5 } & Statistic & P-value & \multicolumn{1}{|c|}{ Statistic } & P-value \\
\hline LM test for SEM & 0.770 & 0.380 & 0.543 & 0.461 \\
\hline LM-ERR & 2.256 & 0.133 & 2.290 & 0.130 \\
LM-EL & 1.343 & 0.246 & 1.982 & 0.159 \\
\hline LM test for SAR & $2.829 *$ & 0.093 & $3.729 * *$ & 0.050 \\
\hline LM-LAG &
\end{tabular}

Notes: LM-ERR = Lagrange multiplier test for spatial error dependence; LM-EL = robust LM-ERR; LM-LAG = Lagrange multiplier test for spatial lag dependence; LM-LE = robust LM-LAG; **Significant at 5\%; *Significant at $10 \%$. 
Table 4. Estimation results

\begin{tabular}{|l|c|c|}
\hline Dependent variable & Resilience (R) & Drop (D) \\
\hline$\alpha$ & $14.08(0.147)$ & $0.31(0.742)$ \\
\hline$G D P p c_{i}$ & $-1.32(0.202)$ & $-0.00(0.994)$ \\
\hline$U R_{i}$ & $-0.03(0.238)$ & $-0.00(0.619)$ \\
\hline$M_{i}$ & $-4.94^{*}(0.056)$ & $-0.21(0.392)$ \\
\hline$C_{i}$ & $-23.06^{* *}(0.010)$ & $1.34^{*}(0.098)$ \\
\hline$S_{i}$ & $7.06^{*}(0.055)$ & $-0.40^{*}(0.093)$ \\
\hline$H C_{i}$ & $-3.60(0.302)$ & $-0.78^{* * *}(0.002)$ \\
\hline$X_{i}$ & $0.02^{*}(0.056)$ & $0.00(0.221)$ \\
\hline$P D_{i}$ & $-1.52(0.207)$ & $0.14^{* *}(0.029)$ \\
\hline$\sum W_{i j} R_{i}$ & $-0.59^{* * *}(0.000)$ & $0.61^{*}(0.076)$ \\
\hline$\sum_{j}^{j} W_{i j} D_{i}$ & & 0.439 \\
\hline $\mathrm{R}_{\mathrm{squared}}$ & 0.558 & \\
\hline
\end{tabular}

Notes: $P$-values in parentheses: ${ }^{* * *}$ Significant at $1 \% ;{ }^{* *}$ Significant at $5 \% ;{ }^{*}$ Significant at $10 \%$.

The effect of the share of manufacturing in GDP is negative, this suggesting that the provinces specialised in this sector were not well prepared to face the shock. In any case, the coefficient linked to this variable is not statistically significant when explaining the Drop indicator. Consequently, our findings convey the message that these provinces are not taking advantage of the recovery phase.

The construction sector displays a negative and robust impact on Resilience. Likewise, the provinces with a higher share of construction have suffered a higher decrease in employment over the recession period as the corresponding coefficient for the Drop indicator turns out to be positive. The explanation for this result lies most probably on the housing bubble that affected the Spanish provinces over too long a period, so that the construction sector became very relevant to explain the provincial employment performance. Our results are in line with those obtained by Angulo et al. (2018).

The service sector (not including government services) reports, as expected, a positive and robust effect on Resilience, as well as a negative and significant effect on Drop. These results convey the message that the provinces that are more specialised in services are better prepared to face economic shocks.

As for the human capital variable, the coefficient turns out to be statistically significant in the Drop equation. The employment reduction was, as expected, lower in the provinces specialised in good skilled labour, thus suggesting that these provinces were better prepared to face up a decreasing demand. Nevertheless, as for the Resilience indicator the effect is not different from zero, it seems that in the recovery phase the amount of skilled labour is not playing a key role in creating employment. 
Just the opposite happens with exports, as the effect is positive for the Resilience indicator but non-significant for the Drop. This suggests that although the more open provinces were not severely hit throughout the downturn, they are the ones better taking advantage over the recovery period. Di Caro (2017) also pointed out the positive effect of exports on Resilience.

With regard to the population density, the findings are somewhat unexpected, as the effect is either non-significant (Resilience) or significant but with a positive sign (Drop) indicating that the higher the population density the higher the vulnerability during the recessions is. A plausible explanation for this negative effect has been offered by Rios et al. (2017: 12), who suggest that it "may arise if the time spent by workers to collect information about vacancies on the job market rises or if problems of crowding and congestion increase excessively".

Finally, the spatial lags of both the Resilience and Drop indicators are significant, this reinforcing the presence of spatial dependence in the proposed model. The sign, however, differs, as is negative in the first case and positive in the second. Therefore, and somewhat in line with what was observed in Table 2, the degree of Resilience (Drop) of each province seems to be negatively (positively) related to that of its neighbours.

\section{CONCLUSIONS}

The Great Recession and its aftermath have brought to the fore several new research topics among which the issue of resilience is one of the most prominent. Our paper deals with it at the provincial level for one of the countries most severely hit by the Recession, namely Spain. To do so, by taking employment as the variable under analysis, we first developed a composite index (Resilience indicator) that allows us to take into account jointly the shock absorption capacity during the recession (Drop indicator) and the capacity to recover when the recession is over (Rebound indicator). The indicators proposed here present drawbacks that, in our view, are outweighed by an important advantage over others: they allow for the starting dates and the duration of recessions and recoveries to differ across the provinces. This feature is instrumental in our analysis, as there are strong differences in those dates among the provinces that, if overlooked, would surely affect the results. Secondly, we tried to assess how differences in the Resilience (and Drop) indicators could be explained. We use a battery of factors mainly related to the degree of development, industry-mix, and openness. As far as we know, this is the first paper using a spatial econometric approach to address this issue.

As for the Resilience, Drop and Rebound indicators, we had two main findings. On the one hand, we find the existence of quite remarkable differences among the provinces. On the other, we obtain that these provinces tend to be with regard to the Rebound indicator but especially to the Drop indicator, rather concentrated around similar levels. In line with the results obtained by Giannakis - Bruggeman (2017) for the Greek regions, heterogeneity of the effects of recessionary shocks calls for the targeted and differentiated provincial development policies. Regarding the spatial concentration issue, it calls for policies jointly designed by neighbouring provinces when they are facing a recession; then, synergies could be readily obtained.

With reference to our attempt to assess the factors behind the Resilience and Drop indicators, two results are robust and conclusive. First, it is the relevance of the construction sector in explaining the provincial employment performance. Second, we find the specialisation in services (other than government ones) as a key feature of provinces that best weathered the 
economic downturn. Another relevant result has to do with the presence of a spatial dependence, in that the response of a province over the whole crisis period is closely related to that of its neighbours. Less conclusive, because it is only true over the downturn, is the positive role played by human capital in that the larger the level the lower the Drop is. A positive relationship is also found between the share of exports and the Resilience indicator, meaning that the higher the first the lower the decline of employment is. This does not happen over the downturn, most likely because it took time for the firms to react to the fall of their internal demand.

According to the estimation results, the main policy conclusions that can be drawn are that, to improve its capacity to face shocks, governments (at national, regional and provincial level) should try to keep the construction sector under control, promote openness, improve the level of human capital and strengthen the role of services. This is tantamount to saying that they should try to implement policies to foster provincial competitiveness. Paraphrasing Krugman (1994), one can say that competitiveness is not everything, but regarding resilience, it is almost everything. ${ }^{26}$

\section{REFERENCES}

Anghel, B. - de la Rica, S. - Lacuesta, A. (2013): Employment Polarisation in Spain along the Cycle 19972012. Journal of the Spanish Economic Association, 5(2): 143-171.

Angulo, A. M. - Mur, J. - Trívez, F. J. (2018): Measuring Resilience to Economic Shocks: An Application to Spain. Annals of Regional Science, 60(2): 349-373.

Artis, M. J. - Marcellino, M. - Proietti, T. (2004): Dating Business Cycles: A Methodological Contribution with an Application to the Euro Area. Oxford Bulletin of Economics and Statistics, 66(4): 537-565.

Bajo-Rubio, O. - Díaz-Roldán, C. (2015): Economic Growth and The Balance-of-Payments Constraint: The Case of the Spanish Regions, 1988-2009. Acta Oeconomica, 65(4): 617-629.

Briguglio, L. - Cordina, G. - Farrugia, N. - Vella, S. (2009): Economic Vulnerability and Resilience: Concepts and Measurements. Oxford Development Studies, 37(3): 229-247.

Bristow, G. - Healy, A. (2017): Innovation and Regional Economic Resilience: An Exploratory Analysis. Annals of Regional Science, 60(2): 265-284.

Caporello, G. - Maravall, A. (2004): Program TSW. Revised Manual. Occasional Paper, No. 0408, Bank of Spain.

Claessens, S. - Kose, M. A. (2013): Financial Crises: Explanations, Types, and Implications. Working Paper, No. 2013-28, IMF.

Combes, J. - Guillaumont, P. (2002): Commodity Price Volatility, Vulnerability, and Development. Development Policy Review, 20: 25-39.

Cuadrado-Roura, J. R. - Maroto, A. (2016): Unbalanced Regional Resilience to the Economic Crisis in Spain: A Tale of Specialization and Productivity. Cambridge Journal of Regions, Economy and Society, 9(1): 153-178.

Dabrowski, M. (2016): The Future of the European Union: Towards a Functional Federalism. Acta Oeconomica, 66(S1): 21-48.

${ }^{26}$ Krugman's exact sentence is “Productivity isn't everything, but in the long run it is almost everything." (Krugman 1994: $11)$. 
Davies, S. (2011): Regional Resilience in the 2008-2010 Downturn: Comparative Evidence from European Countries. Cambridge Journal of Regions, Economy and Society, 4: 369-382.

De Ville, F. - Vermeiren, M. (2016): Rising Powers and Economic Crisis in the Euro Area. Palgrave.

Di Caro, P. (2017): Testing and Explaining Economic Resilience with an Application to Italian Regions. Papers in Regional Science, 96(1): 93-113.

Di Caro, P. - Fratesi, U. (2017): Regional Determinants of Economic Resilience. Annals of Regional Science, 60(2): 235-240.

Eriksson, R. H. - Hane-Weijman, E. (2017): How Do Regional Economies Respond to Crises? The Geography of Job Creation and Destruction in Sweden (1990-2010). European Urban and Regional Studies, 24(1): 87-103.

Frankel, J. - Saravelos, S. (2012): Can Leading Indicators Assess Country Vulnerability? Evidence from the 2008-09 Global Financial Crisis. Journal of International Economics, 87(2): 216-231.

Fratesi, U. - Perucca, G. (2017): Territorial Capital and the Resilience of European Regions. Annals of Regional Science, 60(2): 241-264.

Fratesi, U. - Rodríguez-Pose, A. (2016): The Crisis and Regional Employment in Europe: What Role for Sheltered Economies? Cambridge Journal of Regions, Economy and Society, 9(1): 33-57.

Friedman, M. (1993): The Plucking Model of Business Fluctuations Revisited. Economic Enquiry, 31(2): 171-177.

Georgescu-Rogen, N. (1967): Analytical Economics: Issues and Problems. Cambridge, MA: Harvard University Press.

Giannakis, E. - Bruggeman, A. (2017): Economic Crisis and Regional Resilience: Evidence from Greece. Papers in Regional Science, 96(3): 451-476.

Gómez, V. - Maravall, A. (1996): Programs Tramo and Seats. Working Paper, No. 9628, Bank of Spain.

Han, Y. - Goetz, S. (2015): The Economic Resilience of US Counties During the Great Recession. The Review of Regional Studies, 45(2): 131-149.

Hassink, R. (2010): Regional Resilience: A Promising Concept to Explain Differences in Regional Economic Adaptability? Cambridge Journal of Regions, Economy and Society, 3(1): 45-58.

Hernandez-Salmeron, M. - Usabiaga, C. (2017) Regional Growth and Convergence in Spain: Is the Decentralisation Model Important? Acta Oeconomica, 67(3): 389-412.

Hill, E. - Wial, H. - Wolman, H. (2008): Exploring Regional Economic Resilience. Working Paper, No. 4, Institute Urban and Regional Development, University of California.

Kahsai, M. - Yu, J. - Middleton, M. - Schaeffer, P. - Jackson, R. (2015): A Framework for Measuring County Economic Resilience. Working Paper, No. 2015-03, Regional Research Institute, West Virginia University.

Kemeny, T. - Storper, M. (2015): Is Specialization Good for Regional Economic Development? Regional Studies, 49(6): 1003-1018.

Krugman, P. (1994): The Age of Diminishing Expectations. Cambridge, MA: MIT.

Lastauskas, P. - Stakenas, J. (2017): Structural Labour Market Reforms in the EU-15: Single-Country vs. Coordinated Counterfactuals. Structural Change and Economic Dynamics, 44: 88-99.

Lesage, J. P. - Pace, R. K. (2009): Introduction to Spatial Econometrics. Boca Raton: Taylor \& Francis Group, CRC Press.

Mackinnon, D. - Derickson, K. (2013): From Resilience to Resourcefulness: A Critique of Resilience Policy and Activism. Progress in Human Geography, 37: 253-270.

Malo, M. A. (2015): Labour Market Measures in Spain 2008-2013: The Crisis and Beyond. Report of the International Labour Organization. 
Martin, R. (2012): Regional Economic Resilience, Hysteresis and Recessionary Shocks. Journal of Economic Geography, 12(1): 1-32.

Martin, R. - Sunley, P. (2015): On the Notion of Regional Economic Resilience: Conceptualization and Explanation. Journal of Economic Geography, 15: 1-42.

Martin, R. - Sunley, P. - Gardiner, B. - Tyler, P. (2016): How Regions React to Recessions: Resilience and the Role of Economic Structure. Regional Studies, 50(4): 561-585.

Modica, M. - Reggiani, A. (2015): Spatial Economic Resilience: Overview and Perspectives. Networks and Spatial Economics, 15(2): 211-233.

Moran, P. (1948): The Interpretation of Statistical Maps. Journal of the Royal Statistical Society B, 10(2): 243-251.

Oxford Dictionary of English (2010) (3rd ed): Oxford University Press.

Reggiani, A. - De Graaff, T. - Nijkamp, P. (2002): Resilience: An Evolutionary Approach to Spatial Economic Systems. Networks and Spatial Economics, 2(2): 211-229.

Reig, E. (2017). La competitividad de las regiones españolas ante la economía del conocimiento (The Competitiveness of the Spanish Regions in the Face of the Knowledge Economy). Fundación BBVA.

Rios, V. - Gianmoena, L. - Iraizoz, B. - Rapún, M. - Pascual, P. - Ubago, Y. (2017): The Determinants of Regional Resilience in Spain During the Great Recession. Report included in the Project Regional Resilience in Europe.

Sensier, M. - Artis, M. (2016): The Resilience of Employment in Wales: Through Recession and into Recovery. Regional Studies, 50(4): 586-599.

Sensier, M. - Bristow, G. - Healy, A. (2016): Measuring Economic Resilience Across Europe: Operationalizing a Complex Concept. Spatial Economic Analysis, 11(2): 128-151.

Storper, M. (2005): Society, Community and Economic Development. Studies in Comparative International Development, 39(4): 30-57. 